\title{
Kidney disease in the elderly: biopsy based data from 14 renal centers in Poland
}

\author{
Agnieszka Perkowska-Ptasinska ${ }^{1 *}$ (D), Dominika Deborska-Materkowska', Artur Bartczak², Tomasz Stompor ${ }^{3}$, \\ Tomasz Liberek ${ }^{4}$, Barbara Bullo-Piontecka ${ }^{4}$, Anna Wasinska ${ }^{5}$, Agnieszka Serwacka ${ }^{5}$, Marian Klinger ${ }^{6}$, Jolanta Chyl ${ }^{7}$, \\ Michal Kuriga ${ }^{8}$, Robert Malecki ${ }^{9}$, Krzysztof Marczewski ${ }^{10}$, Bogdan Hryniewicz ${ }^{11}$, Tadeusz Gregorczyk ${ }^{12}$, \\ Monika Wieliczko ${ }^{13}$, Stanislaw Niemczyk ${ }^{14}$, Olga Rostkowska ${ }^{1}$, Leszek Paczek ${ }^{15}$ and Magdalena Durlik ${ }^{1}$
}

\begin{abstract}
Background: Longer life expectancy is associated with an increasing prevalence of kidney disease. Aging itself may cause renal damage, but the spectrum of kidney disorders that affect elderly patients is diverse. Few studies, mostly form US, Asia and West Europe found differences in the prevalence of some types of kidney diseases between elderly and younger patients based on renal biopsy findings, with varied proportion between glomerulopathies and arterionephrosclerosis as a dominant injury found. Here, for the first time in Eastern Europe we analyzed native kidney biopsy findings and their relationship to clinical characteristics at the time of biopsy in elderly individuals (aged $\geq 65$ ) in comparison to younger adults (aged 18-64).

Methods: Biopsy and clinical data from 352 patients aged $\geq 65$ were retrospectively identified, analyzed and compared with a control group of 2214 individuals aged 18-64. All kidney biopsies studied were examined at Medical University of Warsaw in years 2009-14.

Results: In elderly patients the leading indication for biopsy was nephrotic range proteinuria without hematuria (34.2\%) and the most prevalent pathologic diagnoses were: membranous glomerulonephritis (MGN) (18.2\%), focal segmental glomerulosclerosis (FSGS) (17.3\%) amyloidosis (13.9\%) and pauci immune glomerulonephritis (12.8\%). Hypertension and age-related lesions very rarely were found an exclusive or dominant finding in a kidney biopsy (1.7\%) and a cause of proteinuria (1.1\%) in elderly individuals. There were $18.2 \%$ diabetics among elderly individuals, and as much as $75 \%$ of them had no morphologic signs of diabetic kidney disease in the renal biopsy. Amyloidosis, MGN, pauci immune GN, crescentic GN and light and/or heavy chain deposition disease (LCDD/HCDD) were more frequent whereas IgA nephropathy (IgAN), lupus nephritis (LN) and thin basement membrane disease (TBMD) were less common among elderly than in younger patients.
\end{abstract}

Conclusions: Proteinuria, a dominating manifestation in elderly patients subjected to kidney biopsy was most commonly related to glomerulopathies. The relatively high prevalence of potentially curative kidney diseases in elderly individuals implicates the importance of renal biopsy in these patients.

Keywords: Kidney disease in elderly, Kidney biopsy, Glomerulonephritis, Hypertensive nephropathy

\footnotetext{
*Correspondence: aggape@poczta.onet.pl; aggaper@gmail.com

'Department of Transplantology, Nephrology and Internal Medicine, Medical

University of Warsaw, Transplantation Institute, Warsaw 02-006, Poland

Full list of author information is available at the end of the article
} 


\section{Background}

Elderly patients constitute the largest age group among all individuals with chronic kidney disease (CKD). The elderly are affected by the same types of kidney diseases as younger individuals, but their clinical course and morphological manifestation may be influenced by aging. Senescence is associated with an eGFR decline by approximately $0.8-1.7 \mathrm{ml} / \mathrm{min}$ per year, which limits renal function reserve and makes an individual more vulnerable to the influence of injurious factors, common in the elderly population, such as hypertension, cardiovascular disease, diabetes, and drugs nephrotoxicity [1, $2]$. The complexity of the background as well as clinical and morphological manifestations of kidney injury impede precise disease recognition, make it difficult to establish prognosis, and hinder proper treatment selection. In a vast majority of cases renal biopsy is irreplaceable in identifying treatable, reversible lesions, as well as in defining both the activity and chronicity of kidney injury. It has been documented that the percentage of patients with the precise kidney disease recognition decreases with age and most of patients aged $\geq 55$ are labelled as 'CKD of unknown origin' or 'nephroangiosclerosis' [3]. Many nephrologists no longer consider older age as a contraindication to immunosuppressive treatment, which is in line with the growing number of kidney biopsies performed in elderly patients [4].

\section{Methods}

\section{Study design}

This is a quantitative, descriptive and cross-sectional study that included a group of 2566 adult patients with kidney biopsies that were considered diagnostic (i.e., containing sufficient amount of renal cortex for light microscopic and immunomorphological evaluation as well as ultrastructural study whenever necessary for establishing the diagnosis), and were processed and interpreted over the period of 2009-2014 in the Nephropathological Laboratory, Department of Transplantology, Nephrology and Internal Medicine at Medical University of Warsaw. Among patients studied we identified 352 elderly individuals (accepting an defining age of $\geq 65$ [5]) as well as a control group of 2214 patients aged 18-64 years. We analyzed kidney-biopsy based diagnoses in terms of their prevalence and clinicopathological associations in both cohorts. The list of clinical data subjected to analysis included patients' gender, age, eGFR (MDRD), a pre-biopsy follow-up duration, the presence of diabetes, hypertension, and urinalysis results. The clinical categories of renal disease at the time of biopsy were defined as follows: nephrotic range proteinuria ( $\geq 3.5 \mathrm{~g} /$ day) with or without hematuria, non-nephrotic proteinuria $(<3.5 \mathrm{~g} /$ day $)$ with or without hematuria, isolated hematuria.
To base our study on most credible and objective measurements, all presumptive and interpretative data, such as those relating to the acuteness/chronicity as well as dynamics of kidney disease evolution, were excluded from the analysis. As the definition of Acute Kidney Injury (AKI) has been changing over the last several years and we were not able to verify the historical data, we didn't include this clinical course characteristic in our analysis.

\section{Pathologic diagnoses}

In all cases light microscopic (LM) evaluation and immunofluorescence (IFL) (for IgG, IgA, IgM, C3, C1q, fibrinogen, kappa and lambda lights chains) were performed. The diagnosis of immune-complex mediated glomerulopathies, such as IgAN, MGN, LN, etc. was based on the IFL and LM findings. In $44.8 \%$ of biopsies an examination in electron microscopy was also done, which was decided whenever the final diagnosis could not have been made without it. Most commonly the ultrastructural analysis was performed due to: 1) an unspecific/incoherent LM and/or IFL findings; 2) a suspicion of different nephropathies overlap (e.g., DKD coexisting with immune-complex mediated glomerulonephritis); 3) a discrepancy between clinical patients' characteristics and morphological findings in LM and IFL; and 4) a suspected paraproteinemia. The list of morphological diagnoses is presented in Additional file 1: Table S1. We decided not to use the distinction between primary and secondary nephropathies assuming that at least some cases considered primary at the time of biopsy might have later changed their category once a detailed diagnostic process was completed.

\section{Statistical analyses}

The statistical analysis was performed using SAS 9.4 software for Windows. Quantitative variables were summarized by medians (ranges), because the parameters did not follow a normal distribution and they were compared using Wilcoxon Rank-Sum test. Qualitative variables were compared using the $\chi^{2}$-test and Fisher's exact test, respectively to the sample size. A $P$-value of $<0.05$ was considered statistically significant.

\section{Results}

Baseline characteristics are presented in Table 1. The spectrum of renal biopsy diagnoses in elderly and younger patients is shown in Table 2. Three leading renal biopsy diagnoses among elderly patients were MGN, FSGS, and amyloidosis, whereas in younger individuals IgAN, FSGS and MGN were most frequent ones. In comparison to younger patients the elderly cohort was characterized by higher prevalence of MGN, amyloidosis, pauci immune GN, crescentic GN, tubulointerstitial 
Table 1 Clinical characteristics at the time of biopsy by age

\begin{tabular}{|c|c|c|c|}
\hline & Elderly (aged $\geq 65)(n=352)$ & Younger (aged 18-64) $(n=2214)$ & $P$ \\
\hline Male/female ratio & $1: 1$ & $1.1 / 1$ & \\
\hline Age of disease onset & median: 69 (range: 19-87) & median: 37 (range: 1-64) & $<0.001$ \\
\hline Pre-biopsy follow-up (months) & median: 5 (range: 0-660) & median: 10 (range: 0-612) & $<0.001$ \\
\hline \multicolumn{4}{|l|}{ Pre-biopsy follow-up } \\
\hline $\begin{array}{l}<3 \text { months } \\
>3 \text { months }\end{array}$ & $\begin{array}{l}165(46.9 \%) \\
187(53.1 \%)\end{array}$ & $\begin{array}{l}848(38.3 \%) \\
1366(61.7 \%)\end{array}$ & 0.002 \\
\hline \multicolumn{4}{|l|}{ Proteinuria } \\
\hline $\begin{array}{l}\text { nephrotic } \\
\text { non-nephrotic }\end{array}$ & $\begin{array}{l}188(55.6 \%) \\
134(39.6 \%)\end{array}$ & $\begin{array}{l}916(42.8 \%) \\
1124(52.5 \%)\end{array}$ & $<0.001$ \\
\hline Hematuria & $159(45.3 \%)$ & $1359(61.8 \%)$ & $<0.001$ \\
\hline Nephrotic range proteinuria without hematuria & $115(34.2 \%)$ & $453(21.3 \%)$ & $<0.001$ \\
\hline Non-nephrotic proteinuria with hematuria & $76(22.5 \%)$ & 787 (37\%) & \\
\hline Nephrotic range proteinuria with hematuria & $73(21.6 \%)$ & $461(21.6 \%)$ & \\
\hline Non-nephrotic proteinuria without hematuria & $58(17.2 \%)$ & $328(15.4 \%)$ & \\
\hline Isolated hematuria & $8(2.4 \%)$ & $72(3.4 \%)$ & \\
\hline eGFR mL/min/1.73 m² & median 39.3 (range 2.5-161.6) & median 66.8 (range 2.7-252) & $<0.001$ \\
\hline $\mathrm{eGFR} \geq 60 \mathrm{~mL} / \mathrm{min} / 1.73 \mathrm{~m}^{2}$ & $92(26.1 \%)$ & $1194(53.9 \%)$ & $<0.001$ \\
\hline eGFR $30-59 \mathrm{~mL} / \mathrm{min} / 1.73 \mathrm{~m}^{2}$ & $113(32.1 \%)$ & $548(24.8 \%)$ & \\
\hline eGFR $15-29 \mathrm{~mL} / \mathrm{min} / 1.73 \mathrm{~m}^{2}$ & $73(20.7 \%)$ & $238(10.8 \%)$ & \\
\hline $\mathrm{eGFR}<15 \mathrm{~mL} / \mathrm{min} / 1.73 \mathrm{~m}^{2}$ & $74(21 \%)$ & $234(10.5 \%)$ & \\
\hline Duration of symptoms $<3$ months & $165(46.9 \%)$ & $847(38.3 \%)$ & 0.002 \\
\hline Duration of symptoms $\geq 3$ months & $187(53.1 \%)$ & $1367(61.7 \%)$ & \\
\hline Hypertension & $287(84.2 \%)$ & $1398(67.1 \%)$ & $<0.001$ \\
\hline Diabetes & $64(18.5 \%)$ & $160(7.5 \%)$ & $<0.001$ \\
\hline Steroid treatment before the biopsy & $59(17.5 \%)$ & $491(23.7 \%)$ & 0.012 \\
\hline Other immunosuppressive treatment during pre-biopsy follow-up & $16(4.8 \%)$ & $187(9.0 \%)$ & 0.008 \\
\hline
\end{tabular}

inflammation, and light chain/heavy chain deposition disease (LCDD/HCDD) as well as lower prevalence of IgAN, lupus nephritis (LN) and thin basement membrane disease (TBMD). The pre-biopsy follow-up data (Additional file 2: Table S2) have been used to define patients' age at the disease onset, and in the frequency analysis of selected nephropathies. Figure 1a illustrates the frequency of selected nephropathies at different agegroups, whereas Fig. 1b demonstrates their frequencies in relation to all nephropathies (renal biopsy based diagnoses) occurring in a particular age group.

\section{Clinical manifestation of kidney disease in elderly and younger patients}

A majority among elderly patients presented nephrotic range proteinuria $(55.6 \%)$ in contrast to younger cohort in which non-nephrotic proteinuria dominated (52.5\%, $P<0.001)$ (Table 1). Among elderly patients with nephrotic range proteinuria the leading diagnoses were MGN (25\%), amyloidosis (20.2\%) and FSGS (20.2\%) in contrast to younger cohort with this clinical syndrome, in which most prevalent were FSGS (17.5\%), MGN (16.9\%) and IgAN (16.8\%). Among elderly patients, a majority of those with nephrotic range proteinuria had no hematuria, and this clinical presentation was most commonly associated with amyloidosis (25.2\%) (Table 3).

Among elderly patients with non-nephrotic range proteinuria the most common diagnoses were pauci immune GN (21.6\%), FSGS (17.2\%) and IgAN (14.9\%), whereas in individuals aged 18-64 years with this clinical syndrome IgAN (36.7\%), FSGS (14.5\%) and LN (9.1\%) were most prevalent ones (Table 4 ).

An isolated hematuria was seen in only $2.4 \%$ of elderly patients studied, and was most commonly associated with nonspecific lesions best defined as 'minor glomerular abnormalities' (MGA). In younger individuals an isolated hematuria was a presenting symptom in only $3.4 \%$ of patients aged $<65$, and was most commonly associated with IgA-N (23.6\%), MGA (18.1\%), and TBMD (14.0\%). 


\section{Renal biopsy diagnoses according to gender in the elderly}

Significant discrepancies between sexes were found in the frequency of amyloidosis AA, more commonly seen in females $(10.8 \%$ vs. $3.4 \%, P=0.011)$ and IgA-N, significantly more frequently recognized in males $(13.1 \%$ vs. $5.7 \%, P=0.027)$.

Types of kidney disease in elderly diabetic individuals Among patients aged $\geq 65$ there were 64 (18.2\%) individuals with diabetes. The median time of diabetes duration at the time of kidney biopsy was 7.16 years (range $0-24$ years). In $11(17 \%)$ of these patients kidney biopsy revealed lesions consistent with pure DKD, in 4 (6\%) patients there were morphological features of DKD coexisting with another type of kidney injury, and in 48 (75\%) elderly diabetic patients there were no microscopic features of DKD (Table 5). Among elderly patients with diabetes and no DKD on kidney biopsy the most prevalent type of kidney disease was pauci immune GN (focal segmental and crescentic) associated with the presence of ANCA.

\section{Discussion}

CKD, together with diabetes and cardiovascular disease constitute three interrelated conditions of strong public health relevance [6]. Reduced estimated eGFR is one of the very important risk factors of cardiovascular disease and death [7]. In US about $30-40 \%$ of adults aged $\geq 70$, and approximately $50 \%$ of those aged $\geq 80$ have CKD [8, 9]. In Poland the prevalence of CKD in the elderly population has been recently estimated at $29.4 \%$ [10]. In the elderly CKD exerts stronger effect on the life expectancy than in younger population [11]. Therefore, early detection of kidney disease, its type recognition, and the implementation of targeted treatment should be regarded as tools necessary to limit CKD complications and to improve outcomes in cardiovascular diseases.

The complexity of renal injury among elderly individuals obscures the clinical picture. Without a renal biopsy the establishment of the proper diagnosis may be impossible, or at least protracted [12-14].

There are no strict criteria qualifying patients to kidney biopsy in any age group. As it has been defined by Bomback et al., kidney biopsy should in general be considered in any patient who presents at least 2 of the

Table 2 Renal biopsy diagnoses by age

\begin{tabular}{|c|c|c|c|}
\hline Diagnosis & Elderly (aged $\geq 65)(n=352)$ & Younger (aged 18-64) $(n=2214)$ & $P$ \\
\hline$\overline{M G N}$ & $64(18.2 \%)$ & $227(10.3 \%)$ & $<0.001$ \\
\hline FSGS & $61(17.3 \%)$ & $339(15.3 \%)$ & 0.342 \\
\hline $\begin{array}{l}\text { Amyloidosis } \\
\text { AL } \\
\text { AA } \\
\text { Non AA, non AL /not defined }\end{array}$ & $\begin{array}{l}49(13.9 \%) \\
10(2.8 \%) \\
25(7.1 \%) \\
14(4 \%)\end{array}$ & $\begin{array}{l}82(3.7 \%) \\
24(1.1 \%) \\
39(1.8 \%) \\
19(0.8 \%)\end{array}$ & $\begin{array}{l}<0.001 \\
0.019 \\
<0.001 \\
<0.001\end{array}$ \\
\hline $\begin{array}{l}\text { Pauci immune GN } \\
\text { crescentic GN } \\
\text { focal segmental GN }\end{array}$ & $\begin{array}{l}45(12.8 \%) \\
26(7.4 \%) \\
19(5.4 \%)\end{array}$ & $\begin{array}{l}150(6.8 \%) \\
82(3.7 \%) \\
68(3 \%)\end{array}$ & $\begin{array}{l}<0.001 \\
0.004 \\
0.037\end{array}$ \\
\hline $\lg A N$ & $33(9.4 \%)$ & $604(27.3 \%)$ & $<0.001$ \\
\hline Crescentic GN (types $||,,|| l \mid)$, & $31(8.8 \%)$ & 109 (4.9\%) & 0.005 \\
\hline MCD & $22(6.3 \%)$ & $132(6 \%)$ & 0.809 \\
\hline DKD & $16(4.6 \%)$ & $62(2.9 \%)$ & 0.100 \\
\hline Unclassified lesions & $14(4 \%)$ & $92(4.2 \%)$ & 1.000 \\
\hline Tubulointerstitial nephritis & $9(2.6 \%)$ & $34(1.5 \%)$ & 0.177 \\
\hline Membrano-proliferative GN & $8(2.3 \%)$ & $67(3 \%)$ & 0.608 \\
\hline Arterionephrosclerosis (hypertensive nephropathy and aging nephropathy) & $6(1.7 \%)$ & $18(0.8 \%)$ & 0.128 \\
\hline MGA & $6(1.7 \%)$ & $79(3.6 \%)$ & 0.077 \\
\hline End-stage kidney & $6(1.7 \%)$ & $39(1.8 \%)$ & 1.000 \\
\hline LN & $5(1.4 \%)$ & $191(8.6 \%)$ & $<0.001$ \\
\hline $\mathrm{LCDD} / \mathrm{HCDD}$ & $4(1.1 \%)$ & $6(0.3 \%)$ & 0.037 \\
\hline Acute tubular injury/necrosis & $4(1.1 \%)$ & $8(0.4 \%)$ & 0.070 \\
\hline Thrombotic microangiopathy & $3(0.9 \%)$ & $39(1.8 \%)$ & 0.263 \\
\hline Normal kidney morphology & $2(0.6 \%)$ & 29 (1.3\%) & 0.303 \\
\hline TBMD & $1(0.3 \%)$ & $40(1.8 \%)$ & 0.036 \\
\hline
\end{tabular}

The table encompasses only the diagnoses which were made in at least $1 \%$ of individuals in any of the two cohorts studied 

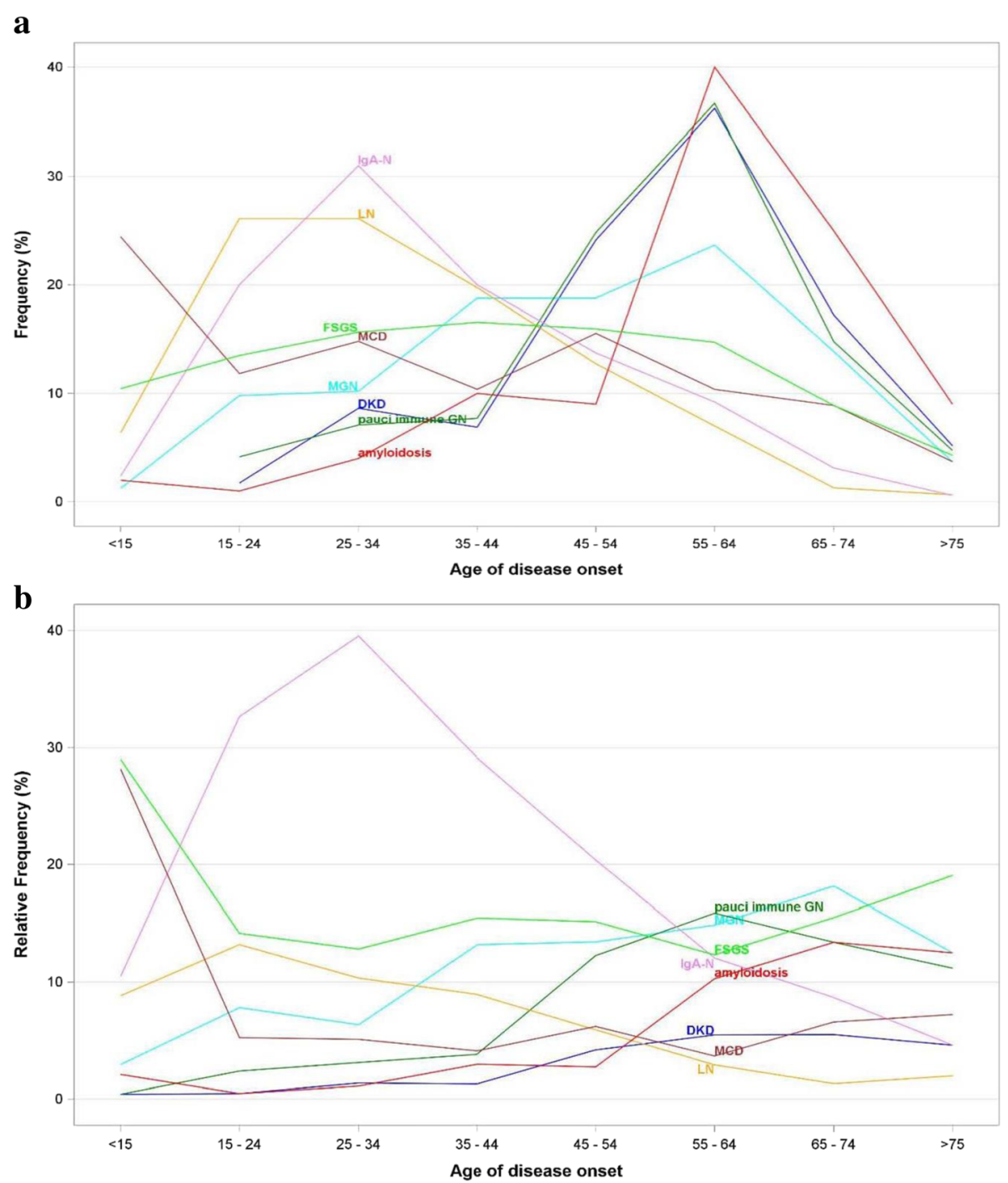

Fig. 1 Frequency (a) and relative frequency (b) distribution of selected kidney biopsy based diagnoses according to age of disease onset

following findings: hematuria, proteinuria $\geq 1 \mathrm{~g} /$ day, renal insufficiency, and/or positive serologies for systemic diseases with known potential for kidney involvement (e.g., hepatitis B or C virus infection, systemic lupus erythematosus and ANCA seropositivity) [15]. As it was emphasized, these indications apply to all agegroups, including elderly (aged $\geq 65$ ) and very elderly (aged $\geq 80$ years) patients. Several studies confirmed that age is not a significant risk factor for biopsy-related complications $[13,16,17]$.

Although kidney biopsy offers the deepest insight into the renal tissue injury, its morphological interpretation may be problematic in the case of significant interference by lesions related to aging, such as global glomerulosclerosis, arteriosclerosis, arteriolar hyalinization, interstitial fibrosis and tubular atrophy. The additional background injury may also be caused by long-lasting hypertension and/or diabetes, as well as several environmental and iatrogenic factors, which are relatively common in the elderly population.

In our elderly patients studied the most common clinical manifestation of renal disease was nephrotic syndrome $(55.6 \%)$ with or without hematuria (21.6 and $34.2 \%$, respectively) which was consistent with the observations of others $[14,16,18-21]$. There are also reports documenting AKI as a leading indication for native kidney biopsies in the elderly with nephrotic syndrome being the second most common manifestation of renal disease in this patient group [14, 22]. What seems to be a problem is the difficulty to define the epidemiology of AKI. This is partly due to the fact that the clinical picture of AKI is very heterogeneous, which has been reflected by the existence of various classification systems based on different diagnostic criteria with the 
Table 3 Distribution of renal biopsy diagnoses among elderly and younger adult patients with nephrotic range proteinuria

\begin{tabular}{|c|c|c|c|c|c|c|c|c|c|}
\hline \multirow[b]{2}{*}{ Renal pathology } & \multicolumn{2}{|c|}{$\begin{array}{l}\text { Nephrotic range proteinuria } \\
\text { with hematuria }\end{array}$} & \multirow[t]{2}{*}{$P$} & \multicolumn{2}{|c|}{$\begin{array}{l}\text { Nephrotic range proteinuria } \\
\text { without hematuria }\end{array}$} & \multirow[t]{2}{*}{$P$} & \multicolumn{2}{|c|}{$\begin{array}{l}\text { Nephrotic range proteinuria } \\
\text { with or without hematuria }\end{array}$} & \multirow[t]{2}{*}{$P$} \\
\hline & $\begin{array}{l}\geq 65 \\
(n=73)\end{array}$ & $18-64(n=461)$ & & $\geq 65(n=115)$ & $18-64(n=453)$ & & $\geq 65(n=188)$ & $18-64(n=916)$ & \\
\hline MGN & $22(30.1 \%)$ & $49(10.6 \%)$ & $<0.001$ & $25(21.7 \%)$ & $106(23.4 \%)$ & 0.804 & $47(25.0 \%)$ & $155(16.9 \%)$ & 0.013 \\
\hline FSGS & $15(20.6 \%)$ & 79 (17.1\%) & 0.508 & $23(20.0 \%)$ & $81(17.9 \%)$ & 0.591 & $38(20.2 \%)$ & $160(17.5 \%)$ & 0.404 \\
\hline Amyloidosis & $9(12.3 \%)$ & $13(2.8 \%)$ & 0.001 & $29(25.2 \%)$ & $44(9.7 \%)$ & $<0.001$ & $38(20.2 \%)$ & $57(6.2 \%)$ & $<0.001$ \\
\hline $\begin{array}{l}\text { Pauci immune GN } \\
\text { crescentic GN } \\
\text { focal segmental GN }\end{array}$ & $\begin{array}{l}7(9.6 \%) \\
3(4.1 \%) \\
4(5.5 \%)\end{array}$ & $\begin{array}{l}31(6.7 \%) \\
18(3.9 \%) \\
13(2.8)\end{array}$ & $\begin{array}{l}0.336 \\
1.000 \\
0.271\end{array}$ & $\begin{array}{l}3(2.6 \%) \\
1(0.9 \%) \\
2(1.7 \%)\end{array}$ & $\begin{array}{l}4(0.9 \%) \\
2(0.4 \%) \\
2(0.4 \%)\end{array}$ & $\begin{array}{l}0.151 \\
0.493 \\
0.184\end{array}$ & $\begin{array}{l}10(5.3 \%) \\
4(2.1 \%) \\
6(3.2 \%)\end{array}$ & $\begin{array}{l}35(3.8 \%) \\
20(2.2 \%) \\
15(1.6 \%)\end{array}$ & $\begin{array}{l}0.317 \\
1.000 \\
0.151\end{array}$ \\
\hline $\lg A N$ & $6(8.2 \%)$ & $114(24.7 \%)$ & 0.001 & $4(3.5 \%)$ & $39(8.6 \%)$ & 0.075 & $10(5.3 \%)$ & $154(16.8 \%)$ & $<0.001$ \\
\hline MCD & $5(6.9 \%)$ & $30(6.5 \%)$ & 0.804 & $11(9.6 \%)$ & $84(18.5 \%)$ & 0.025 & $16(8.5 \%)$ & $114(12.5 \%)$ & 0.137 \\
\hline Membrano-proliferative GN & $5(6.9 \%)$ & $30(6.5 \%)$ & 0.804 & $1(0.9 \%)$ & $11(2.4 \%)$ & 0.475 & $6(3.2 \%)$ & $41(4.5 \%)$ & 0.553 \\
\hline DKD & $2(2.7 \%)$ & $26(5.6 \%)$ & 0.405 & $13(11.3 \%)$ & $23(5.1 \%)$ & 0.029 & $15(8.0 \%)$ & $49(5.4 \%)$ & 0.170 \\
\hline LN & $1(1.4 \%)$ & $51(11.1 \%)$ & 0.005 & 0 & $23(5.1 \%)$ & 0.007 & $1(0.5 \%)$ & $74(8.1 \%)$ & $<0.001$ \\
\hline End-stage kidney & $1(1.4 \%)$ & $4(0.9 \%)$ & 0.522 & $1(0.9 \%)$ & $8(1.8 \%)$ & 0.695 & $2(1.1 \%)$ & $12(1.3 \%)$ & 1.000 \\
\hline Arterionephrosclerosis & $1(1.4 \%)$ & $2(0.4 \%)$ & 0.357 & $1(0.9 \%)$ & $5(1.1 \%)$ & 1.000 & $2(1.1 \%)$ & $7(0.8 \%)$ & 0.655 \\
\hline MGA & 0 & $3(0.7 \%)$ & 1.000 & $1(0.9 \%)$ & $11(2.4 \%)$ & 0.475 & $1(0.5 \%)$ & $15(1.6 \%)$ & 0.498 \\
\hline Thrombotic microangiopathy & 0 & $9(2.0 \%)$ & 0.618 & $1(0.9 \%)$ & $6(1.3 \%)$ & 1.000 & $1(0.5 \%)$ & $15(1.6 \%)$ & 0.498 \\
\hline Unclassified lesions & 0 & $13(2.8 \%)$ & 0.232 & $3(2.6 \%)$ & $14(3.1 \%)$ & 1.000 & $3(1.6 \%)$ & $27(3.0 \%)$ & 0.458 \\
\hline
\end{tabular}

most recent one announced by KDIGO in 2012 [23]. Our study covered the period between 2009 and 2014, the clinical data were provided by different renal centers, and the descriptions of a disease course were not uniform and precise enough to allow for a reliable distinction between AKI, AKI superimposed on CKD and 'pure' CKD.

Although the spectrum of diseases affecting people aged $\geq 65$ is the same as in younger population, there are some distinct differences in the frequency of certain nephropathies between these two age groups. Our observation of the relatively high incidence of MGN among elderly individuals is in line with the reports of others $[12,13,22,24,25]$. Our data indicate that the peak frequency of MGN occurs at the age 55-64 years, and a peak relative frequency at the age of 65-74 years (Fig. 1). The histological recognition of MGN provides important rationale for the use of immunosuppressive therapy, especially if progressive eGFR lowering is observed.

Focal segmental glomerulosclerosis was recognized as the second most common histological diagnosis in both elderly and younger patients (17.3 and $15.3 \%$ respectively). As in our study, an association between FSGS and nephrotic-range proteinuria, as well as no difference in FSGS frequency between patients aged $\geq 65$ and those aged $<65$ were observed by others $[13,16,17]$. In a vast majority of our cases studied morphological and clinical features suggested the secondary nature of glomerular sclerosis, but the etiology of this process was ambiguous. Although in many elderly patients a contribution of aging, hypertension and arteriosclerosis to the FSGS development could not be excluded, the histological picture was not specific enough to justify a diagnosis of hypertensive nephropathy or arterionephrosclerosis.

In a few published studies that analyzed the prevalence of kidney biopsy based diagnoses in elderly individuals the percentage of cases, in which age and/or hypertension related lesions were dominant microscopic finding ranged from $1.6 \%$ in Chinese patients to $6.2 \%$ in Japanese cohort $[19,24,26]$. The proportion of aforementioned diagnosis in our elderly group was $1.7 \%$ (Table 2), despite the fact that as much as $84.2 \%$ of patients aged $\geq 65$ suffered from hypertension (Table 1.)

Amyloidosis was found to be the third most common histological diagnosis in our elderly patients with a prevalence of $13.9 \%$ as compared with $3.7 \%$ in younger individuals $(P<0.001)$. These findings are in line with the reports of others $[13,17,20]$. Our data show the peak frequency of amyloidosis at the age of 55-64, whereas the highest relative frequency of this disease occurred at the age of 65-74 (Fig. 1). Amyloidosis was found to be the leading (25.2\%) histological finding among elderly patients with nephrotic range proteinuria without hematuria (Table 3.). Although a nephroticrange proteinuria without hematuria was the most common presentation of amyloidosis in the elderly (61.7\%), in a substantial percentage of cases (19\%) the disease was manifested by non-nephrotic proteinuria. The latter finding should be emphasized, since many nephrologists refrain from kidney biopsy in an elderly 
Table 4 Distribution of renal biopsy diagnoses among elderly and younger patients with non-nephrotic range proteinuria

\begin{tabular}{|c|c|c|c|c|c|c|c|c|c|}
\hline \multirow[b]{2}{*}{ Renal pathology } & \multicolumn{2}{|c|}{$\begin{array}{l}\text { Non-nephrotic range } \\
\text { proteinuria with hematuria }\end{array}$} & \multirow[t]{2}{*}{$P$} & \multicolumn{2}{|c|}{$\begin{array}{l}\text { Non-nephrotic range } \\
\text { proteinuria without } \\
\text { hematuria }\end{array}$} & \multirow[t]{2}{*}{$P$} & \multicolumn{2}{|c|}{$\begin{array}{l}\text { Non-nephrotic range } \\
\text { proteinuria with or without } \\
\text { hematuria }\end{array}$} & \multirow[t]{2}{*}{$P$} \\
\hline & $\begin{array}{l}\geq 65 \\
(n=76)\end{array}$ & $18-64(n=787)$ & & $\begin{array}{l}\geq 65 \\
(n=58)\end{array}$ & $18-64(n=328)$ & & $\begin{array}{l}\geq 65 \\
(n=134)\end{array}$ & $18-64(n=1124)$ & \\
\hline $\begin{array}{l}\text { Pauci immune GN } \\
\text { crescentic GN } \\
\text { focal segmental GN }\end{array}$ & $\begin{array}{l}25(32.9 \%) \\
15(19.7 \%) \\
10(13.2 \%)\end{array}$ & $\begin{array}{l}92(11.7 \%) \\
52(6.6 \%) \\
40(5.1 \%)\end{array}$ & $\begin{array}{l}<0.001 \\
<0.001 \\
0.009\end{array}$ & $\begin{array}{l}4(6.9 \%) \\
2(3.5 \%) \\
2(3.5 \%)\end{array}$ & $\begin{array}{l}7(2.1 \%) \\
2(0.6 \%) \\
5(1.5 \%)\end{array}$ & $\begin{array}{l}0.067 \\
0.109 \\
0.284\end{array}$ & $\begin{array}{l}29(21.6 \%) \\
17(12.7 \%) \\
12(9.0 \%)\end{array}$ & $\begin{array}{l}99(8.8 \%) \\
54(4.8 \%) \\
45(4.0 \%)\end{array}$ & $\begin{array}{l}<0.001 \\
0.001 \\
0.015\end{array}$ \\
\hline $\lg A N$ & 15 (19.7\%) & $336(42.7 \%)$ & $<0.001$ & $5(8.6 \%)$ & $74(22.6 \%)$ & 0.013 & $20(14.9 \%)$ & $413(36.7 \%)$ & $<0.001$ \\
\hline FSGS & $11(14.5 \%)$ & $97(12.3 \%)$ & 0.586 & $12(20.7 \%)$ & $65(19.8 \%)$ & 0.860 & $23(17.2 \%)$ & $163(14.5 \%)$ & 0.439 \\
\hline Unclassified lesions & $7(9.2 \%)$ & $29(3.7 \%)$ & 0.032 & $3(5.2 \%)$ & $24(7.3 \%)$ & 0.781 & $10(7.5 \%)$ & $53(4.7 \%)$ & 0.204 \\
\hline MGN & $4(5.3 \%)$ & $27(3.4 \%)$ & 0.342 & $10(17.2 \%)$ & $40(12.2 \%)$ & 0.292 & $14(10.5 \%)$ & $67(6.0 \%)$ & 0.046 \\
\hline LN & $2(2.6 \%)$ & $73(9.3 \%)$ & 0.049 & $2(3.5 \%)$ & $28(8.5 \%)$ & 0.285 & $4(3.0 \%)$ & $102(9.1 \%)$ & 0.013 \\
\hline Tubulointerstitial nephritis & $2(2.6 \%)$ & $4(0.5 \%)$ & 0.091 & $4(6.9 \%)$ & $10(3.1 \%)$ & 0.242 & $6(4.5 \%)$ & $16(1.4 \%)$ & 0.023 \\
\hline $\mathrm{LCDD} / \mathrm{HCDD}$ & $2(2.6 \%)$ & $2(0.3 \%)$ & 0.041 & $1(1.7 \%)$ & $1(0.3 \%)$ & 0.278 & $3(2.2 \%)$ & $3(0.3 \%)$ & 0.019 \\
\hline Membrano-proliferative GN & $2(2.6 \%)$ & 15 (1.9\%) & 0.656 & 0 & $9(2.7 \%)$ & 0.366 & $2(1.5 \%)$ & $24(2.1 \%)$ & 1.000 \\
\hline End-stage kidney & $2(2.6 \%)$ & $18(2.3 \%)$ & 0.694 & $2(3.5 \%)$ & $7(2.1 \%)$ & 0.630 & $4(3 \%)$ & $25(2.2 \%)$ & 0.540 \\
\hline TBMD & $1(1.3 \%)$ & $23(2.9 \%)$ & 0.715 & 0 & $2(0.6 \%)$ & 1.000 & $1(0.8 \%)$ & $25(2.2 \%)$ & 0.513 \\
\hline MCD & $1(1.3 \%)$ & $5(0.6 \%)$ & 0.426 & $4(6.9 \%)$ & $8(2.4 \%)$ & 0.089 & $5(3.7 \%)$ & $13(1.2 \%)$ & 0.035 \\
\hline Amyloidosis & $1(1.3 \%)$ & $7(0.9 \%)$ & 0.523 & $8(13.8 \%)$ & $15(4.6 \%)$ & 0.013 & $9(6.7 \%)$ & $23(2.1 \%)$ & 0.005 \\
\hline MGA & 0 & 31 (3.9\%) & 0.102 & $1(1.7 \%)$ & $16(4.9 \%)$ & 0.281 & $1(0.8 \%)$ & $48(4.3 \%)$ & 0.046 \\
\hline DKD & 0 & $8(1.0 \%)$ & 1.000 & $1(1.7 \%)$ & $5(1.5 \%)$ & 1.000 & $1(0.8 \%)$ & $13(1.2 \%)$ & 1.000 \\
\hline Thrombotic microangiopathy & 0 & $10(1.3 \%)$ & 1.000 & $1(1.7 \%)$ & $9(2.7 \%)$ & 1.000 & $1(0.8 \%)$ & $20(1.8 \%)$ & 0.718 \\
\hline Arterionephrosclerosis & 0 & $2(0.3 \%)$ & 1.000 & $2(3.5 \%)$ & $6(1.8 \%)$ & 0.344 & $2(1.5 \%)$ & $8(0.7 \%)$ & 0.289 \\
\hline Normal kidney morphology & 0 & $12(1.5 \%)$ & 0.614 & 0 & $2(0.6 \%)$ & 1.000 & 0 & $14(1.3 \%)$ & 0.385 \\
\hline Alport syndrome & 0 & $8(1.0 \%)$ & 1.000 & 0 & $2(0.6 \%)$ & 1.000 & 0 & $10(0.9 \%)$ & 1.000 \\
\hline
\end{tabular}

patient with mild proteinuria, in whom concomitant amyloidosis-related cardiomyopathy can be easily misinterpreted as an ischemic heart disease.

Several authors reported the proportion of diabetic kidney disease ranging between $2.2 \%$ up to $10 \%$ in renal biopsy registries $[19,24]$. The results of ours implicate that in people aged $\geq 65$ DKD constitutes $4.6 \%$ of all renal-biopsy diagnoses. In our cohort the peak frequency and the highest relative frequency of this disease occurred at the age of 55-64 years (Fig. 1). The usual indications for renal biopsy in diabetic patients include: an abrupt onset or rapid progression of kidney disease, the presence of active urinary sediment, and the progression of proteinuria in the absence of diabetic retinopathy or neuropathy. Since the group of diabetic patients in our cohort is not representative for the whole population of diabetics, it should be noted that $75 \%$ of our elderly diabetic patients had non-diabetic kidney disease upon kidney biopsy, which is in line with the observation made by Sharma et al. [27]. These results may be partially explained by the relatively short duration of diabetes at the time of kidney biopsy in our patients (median 7.16 years for diabetic patients studied, range 0-24 years), as well as by the fact that in $40 \%$ of biopsies from diabetic individuals electron microscopy was not performed, which does not allow for the exclusion of early phase of DKD.

One of the leading histological diagnoses in general, and the most common renal disease manifested by non-

Table 5 Renal biopsy diagnoses among patients with diabetes

\begin{tabular}{llll}
\hline $\begin{array}{l}\text { Patients with } \\
\text { diabetes }\end{array}$ & \multicolumn{3}{l}{ Kidney biopsy diagnosis } \\
\cline { 2 - 4 } & $\begin{array}{l}\text { Diabetic kidney disease } \\
\text { absent }\end{array}$ & $\begin{array}{l}\text { Diabetic kidney disease } \\
\text { present }\end{array}$ & $\begin{array}{l}\text { Coincidence of diabetic kidney disease } \\
\text { and other nephropathy }\end{array}$ \\
\hline$\geq 65(n=64)$ & $48(75.0 \%)$ & $11(17.0 \%)$ & $4(6.0 \%)^{\mathrm{a}}$ \\
$18-64(n=160)$ & $98(61.3 \%)$ & $52(32.5 \%)$ & $10(6.3 \%)^{\mathrm{b}}$ \\
\hline
\end{tabular}

${ }^{a} 2$ cases of MGN, 1 case of MCD and 1 case of IgAN

${ }^{\mathrm{b}} 6$ cases of $\operatorname{lgA}-\mathrm{N}, 1$ case of LCDD, 1 case of MCD, 2 cases of MGN 
nephrotic range proteinuria with hematuria in our elderly patients was pauci-immune GN. Notably, 23.8\% of elderly and $24.8 \%$ of younger patients with pauci-immune GN suffered from nephrotic-range proteinuria. Pauci-immune GN being one of the leading diagnoses made upon kidney biopsy among elderly individuals was reported by others [13, 25, 28, 29]. The peak frequency and the highest relative frequency of this disease in our patients studied occurred at the age of 55-64 years (Fig. 1). In a vast majority of cases pauci immune $\mathrm{GN}$ is associated with the presence of ANCA vasculitis, with peak incidence of 52.9 per million being observed among people aged 65-74 [30]. It is worth mentioning that in contrast to younger individuals, in the elderly vasculitis more commonly manifests with renal disease, and less frequently involves upper respiratory tract [29]. Vasculitis-related symptoms such as myalgia and headache may be easily misdiagnosed as common afflictions of the elderly, e.g., polymyalgia rheumatica [31].

\section{Conclusions}

Our analysis confirmed differences in the prevalence of certain kidney diseases between elderly and younger individuals. Elderly patients were more frequently nephrotic, hypertensive and diabetic, and have lower eGFR at the time of the biopsy than younger individuals. A leading clinical manifestation in patients aged $\geq 65$ years submitted to kidney biopsy was proteinuria, most commonly of nephrotic range, which in majority of cases was related to glomerulopathies, Hypertension and agerelated lesions rarely were found an exclusive or dominant finding in a kidney biopsy or a cause of proteinuria in individuals aged $\geq 65$ years. The relatively high prevalence of potentially curative kidney diseases in the elderly individuals implicates the importance of renal biopsy in these patients.

\section{Additional files}

Additional file 1: Table S1. The list of kidney biopsy diagnoses.

Contains morphological diagnoses which occurred at least once in the study group. (DOC $33 \mathrm{~kb}$ )

Additional file 2: Table S2. Pre-biopsy follow-up in selected nephropathies in elderly and younger patients. (DOCX $12 \mathrm{~kb}$ )

\begin{abstract}
Abbreviations
AKI: Acute kidney injury; CKD: Chronic kidney disease; DKD: Diabetic kidney disease; FSGS: Focal segmental glomerulosclerosis; GN: Glomerulonephritis; IFL: Immunofluorescence; IgAN: IgA nephropathy; LCDD/HCDD: Light and/or heavy chain deposition disease; LM: Light microscopy; LN: Lupus nephritis; MCD: Minimal change disease; MGA: Minor glomerular abnormalities; MGN: Membranous glomerulonephritis; TBMD: Thin basement membrane disease
\end{abstract}

\section{Funding}

The study was financially supported by statutory fund no. 1W22/2015 granted by Medical University of Warsaw.

\section{Availability of data and materials}

The datasets supporting the conclusions of this article is(are) included within the article (and its additional files.

\section{Authors' contributions}

Conception and design: APP and DDM. Acquisition of data: APP, AW, AS, $B B P, J C, M K, R M, K M, B H, T G, M W, S N, O R$. Data analysis and interpretation: APP, DDM, AB, TS, TL, MW. Writing the manuscript: APP and DDM. Critical review of the manuscript: MK, AW, AS, BBP, JC, RM, MK, KM, BH, TG, MW, SN, $\mathrm{OR}, \mathrm{AB}$. All authors read and approved the final manuscript.

\section{Competing interests}

The authors declare that they have no competing interests.

\section{Consent for publication}

Not applicable.

\section{Ethics approval and consent to participate}

The study was approved by the Ethical Committee of Medical University of Warsaw and complied with the provisions of the Good Clinical Practice Guidelines and the Declaration of Helsinki. All patients provided informed consent prior to participation.

\section{Author details}

'Department of Transplantology, Nephrology and Internal Medicine, Medical University of Warsaw, Transplantation Institute, Warsaw 02-006, Poland. ${ }^{2}$ Department of Pathology, The Medical Center of Postgraduate Education, Warsaw 01-813, Poland. ${ }^{3}$ Department of Nephrology, Hypertension and Internal Medicine, University of Warmia and Mazury in Olsztyn, Olsztyn 10-561, Poland. ${ }^{4}$ Department of Nephrology, Transplantology and Internal Medicine, Medical University of Gdansk, Gdansk 80-211, Poland. ${ }^{5}$ Department of Internal Diseases, Nephrology and Transplantology, Central Clinical Hospital of the Ministry of Interior, Warsaw 02-507, Poland. ${ }^{6}$ Department of Nephrology and Transplantation Medicine, Wroclaw Medical University, Wroclaw 50-556, Poland. ${ }^{7}$ Dialysis Unit, Specialist Hospital in Radom, Radom 26-600, Poland. ${ }^{8}$ Department of Nephrology, District Hospital in Plock, Plock 09-400, Poland. ${ }^{9}$ Department of Internal Medicine and Nephrology, Specialist Hospital in Miedzylesie, Warszawa 04-749, Poland. ${ }^{10}$ Department of Nephrology, Endocrinology, Hypertension and Internal Diseases, Public District Hospital in Zamosc, Zamosc 22-410, Poland. " Department of Nephrology and Dialysis, District Specialist Hospital in Slupsk, Slupsk 76-200, Poland. ${ }^{12}$ Department of Nephrology, District Hospital in Kielce, Kielce 75-736, Poland. ${ }^{13}$ Department of Nephrology, Dialysis, and Internal Diseases, Medical University of Warsaw, Warsaw 02-097, Poland. ${ }^{14}$ Department of Internal Diseases, Nephrology and Dialysis, Military Institute of Medicine, Warsaw 04-141, Poland. ${ }^{15}$ Department of Immunology, Transplantology and Internal Medicine, Medical University of Warsaw, Transplantation Institute, Warsaw 02-006, Poland.

Received: 9 August 2016 Accepted: 18 November 2016 Published online: 25 November 2016

\section{References}

1. Hemmelgarn BR, Zhang J, Manns BJ, Tonelli M, Larsen E, Ghali WA, et al. Progression of kidney dysfunction in the community-dwelling elderly. Kidney Int. 2006;9:2155-61.

2. Pani A, Bragg-Gresham J, Masala M, Piras D, Atzeni A, Pilia MG, et al. Prevalence of CKD and its relationship to eGFR-related genetic loci and clinical risk factors in the SardiNIA study cohort. J Am Soc Nephrol. 2014;25:1533-44.

3. Esposito C, Torreggiani M, Arazzi M, Serpieri N, Scaramuzzi ML, Manini A, Grosjean F, Esposito V, Catucci D, La Porta E, Dal CA. Loss of renal function in the elderly Italians: a physiologic or pathologic process? J Gerontol A Biol Sci Med Sci. 2012;67:1387-93.

4. Heldal K, Hartmann A, Grootendorst DC, de Jager DJ, Leivestad T, Foss A, et al. Benefit of kidney transplantation beyond 70 years of age. Nephrol Dial Transplant. 2010;25:1680-7.

5. World Health Organization. Health statistics and information systems. WHO; 2016. http://www.who.int/healthinfo/survey/ageingdefnolder/en/.

6. Stevens LA, Viswanathan G, Weiner DE. Chronic kidney disease and end-stage renal disease in the elderly population: current prevalence, 
future projections, and clinical significance. Adv Chronic Kidney Dis. 2010;17:293-301.

7. Go AS, Chertow GM, Fan D, McCulloch CE, Hsu CY. Chronic kidney disease and the risks of death, cardiovascular events, and hospitalization. N Engl J Med. 2004;351:1296-305.

8. Grams ME, Chow EK, Segev DL, Coresh J. Lifetime incidence of CKD stages 3-5 in the United States. Am J Kidney Dis. 2013;62:245-52.

9. Coresh J, Astor BC, Greene T, Eknoyan G, Levey AS. Chronic kidney disease awareness, prevalence, and trends among U.S. adults, 1999 to 2000. J Am Soc Nephrol. 2005;16:180-8.

10. Chudek J, Wieczorowska-Tobis K, Zejda J, Broczek K, Skalska A, Zdrojewski T, et al. The prevalence of chronic kidney disease and its relation to socioeconomic conditions in an elderly Polish population: results from the national population-based study PolSenior. Nephrol Dial Transplant. 2014:29:1073-82.

11. Bacchetti P, Garg AX, Kaufman JS, Walter LC, Mehta KM, Steinman MA, et al. Age affects outcomes in chronic kidney disease. JASN. 2007;18:2758-65.

12. Moutzouris DA, Herlitz L, Appel GB, Markowitz GS, Freudenthal B, Radhakrishnan J, et al. Renal biopsy in the very elderly. Clin J Am Soc Nephrol. 2009;4:1073-82.

13. Nair R, Bell JM, Walker PD. Renal biopsy in patients aged 80 years and older. Am J Kidney Dis. 2004;44:618-26.

14. Haas M, Spargo BH, Wit EJ, Meehan SM. Etiologies and outcome of acute renal insufficiency in older adults: a renal biopsy study of 259 cases. Am J Kidney. 2000;35:433-47.

15. Bomback AS, Herlitz LC, Markowitz GS. Renal biopsy in the elderly and very elderly: useful or not? Adv Chronic Kidney Dis. 2012;19:61-7.

16. Uezono S, Hara S, Sato Y, Komatsu H, Ikeda N, Shimao Y, et al. Renal biopsy in elderly patients: a clinicopathological analysis. Ren Fail. 2006;8:549-55.

17. Rychlik I, Jancova E, Tesar V, Kolsky A, Lacha J, Stejskal J, et al. Occurrence of renal diseases in the years 1994-2000. Nephrol Dial Transplant. 2004;19:3040-9.

18. Levison SP. Renal disease in the elderly: the role of the renal biopsy. Am J Kidney Dis. 1990;16:300-6.

19. Jin B, Zeng C, Ge Y, Le W, Xie H, Chen H, et al. The spectrum of biopsyproven kidney diseases in elderly Chinese patients. Nephrol Dial Transplant. 2014;29:2251-9.

20. Komatsuda A, Nakamoto Y, Imai H, Yasuda T, Yanagisawa MM, Wakui H, et al. Kidney diseases among the elderly - a clinicopathological analysis of 247 elderly patients. Intern Med. 1993;32:377-81.

21. Prakash J, Singh AK, Saxena RK. Usha. Glomerular diseases in the elderly in India. Int Urol Nephrol. 2003;35:283-8.

22. Brown CM, Scheven L, O'Kelly P, Dorman AM, Walshe JJ. Renal histology in the elderly: indications and outcomes. J Nephrol. 2012;25:240-4.

23. Wald R, Quinn RR, Adhikari NK, Burns KE, Friedrich JO, Garg AX, et al. Risk of chronic dialysis and death following acute kidney injury. Am J Med. 2012:125:585-93.

24. Yokoyama H, Sugiyama H, Sato H, Taguchi T, Nagata M, Matsuo S, et al. Renal disease in the elderly and the very elderly Japanese: analysis of the Japan Renal Biopsy Registry (J-RBR). Clin Exp Nephrol. 2012;16:903-20.

25. Shin $\mathrm{JH}$, Pyo HJ, Kwon Yl, Chang MK, Kim HK, Won NH, et al. Renal biopsy in elderly patients: clinicopathological correlation in 117 Korean patients. Clin Nephrol. 2001;56:19-26.

26. Harmankaya O, Okuturlar Y, Kocoglu H, Kaptanogullari H, Yucel SK, Ozkan H, et al. Renal biopsy in the elderly: a single-center experience. Int Urol Nephrol. 2015;47:1397-401.

27. Sharma SG, Bomback AS, Radhakrishnan J, Herlitz LC, Stokes MB, Markowitz $G S$, et al. The modern spectrum of renal biopsy findings in patients with diabetes. Clin J Am Soc Nephrol. 2013;8:1718-24.

28. Vendemia F, Gesualdo L, Schena FP, D'Amico G. Epidemiology of primary glomerulonephritis in the elderly. Report from the Italian Registry of Renal Biopsy. J Nephrol. 2001:14:340-52.

29. Ozturk S, Sumnu A, Seyahi N, Gullulu M, Sipahioglu M, Artan S, et al. Demographic and clinical characteristics of primary glomerular diseases in Turkey. Int Urol Nephrol. 2014;46:2347-55.

30. Watts RA, Lane SE, Bentham G, Scott DG. Epidemiology of systemic vasculitis: a ten-year study in the United Kingdom. Arthritis Rheum. 2000;43:414-9

31. Chen M, Yu F, Zhang Y, Zhao MH. Antineutrophil cytoplasmic autoantibody associated vasculitis in older patients. Medicine (Baltimore). 2008;87:203-9.

\section{Submit your next manuscript to BioMed Central and we will help you at every step:}

- We accept pre-submission inquiries

- Our selector tool helps you to find the most relevant journal

- We provide round the clock customer support

- Convenient online submission

- Thorough peer review

- Inclusion in PubMed and all major indexing services

- Maximum visibility for your research

Submit your manuscript at www.biomedcentral.com/submit

Biomed Central 